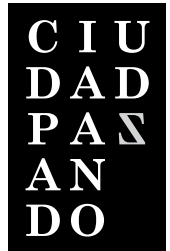

\title{
"La reforma agraria no es una necesidad del socialismo, es un principio básico del capitalismo. Entrevista a Andrés París, miembro de las FARC"
}

Entrevista realizada por

\section{Johan Antolinez y Jaime Wilches}

Editores revista Ciudad Paz-ando

El acuerdo de paz entre el gobierno Santos y las Farc es una realidad. ¿Estamos preparados para este momento histórico?, ¿toleramos que las voces de la insurgencia participen en la arena política?, ¿podremos convivir con la resistencia de fuerzas de derecha a cualquier posibilidad de salida política al conflicto armado? En diálogo con Jesús Camilo (Andrés París), integrante del secretariado de las Farc y de la mesa de negociación en La Habana, se plantean estas inquietudes y se visualizan los escenarios a los que están comprometidos, no solo las partes que firmaron el acuerdo, sino los sectores sociales que tendrán que convivir con una nueva realidad política, pero con implicaciones económicas y sociales.

Johan Antolinez (J.A): Andrés (Alias) o Jesús Camilo (Nombre original) ¿Cómo quiere que lo llamemos?

Andrés París (A.P): ¿Qué contesto? Yo personalmente voy a tomar mi nombre original. Es mejor porque el tiempo lo va desgastando. Hasta en Cuba, en las primeras ruedas de prensa, los medios no sabían cómo referirse a nosotros. Pero en esta entrevista, para evitar confusiones dejémoslo en Andrés París.

(J.A): La pregunta, tal vez reiterativa en muchas entrevistas que le habrán realizado, pero que es importante para comprender el proceso de paz es ¿cómo se vivió en el día a día este proceso, cuando las cámaras no estaban presentes? Ya Humberto de La Calle ha revelado algunos detalles, en los que señala que la negociación fue más compleja de lo que se esperaba.

(A.P): Todo eso es muy accidentado, y todavía él está dando una imagen distinta porque está pendiente de la precandidatura, pero nosotros también conocimos al negociador con una personalidad que pocos han visto ante las cámaras y las redes sociales. Pero somos conscientes de estas nuevas realidades, y después del proceso de negociación entendemos que construir la imagen de un candidato ya no es tan demorado como antes. Lo cibernético mató a la plaza pública.

Lo principal es que el esfuerzo de estos años dio como resultado un acuerdo que abre las puertas a una nueva Colombia; no obstante, como lo dicen algunos historiadores y políticos, el acuerdo no significa que todo esté solucionado, pues hay sectores y factores que resisten a que lo negociado en La Habana democratice el país.

Los diálogos de La Habana son un precedente importantísimo en experiencias de procesos de negociación. Lo que queda por delante es un reto muy grande para 
que ese acuerdo se materialice y para eso necesitamos el concurso de fuerzas políticas, sociales y económicas mayores de las que han apoyado este acuerdo. Esta nueva época se abre con una importante confrontación política que profundiza el choque de tendencias reaccionarias y progresistas dentro de una perspectiva de correlación de fuerzas más favorable a las tendencias que quieren el cambio. Pero esa lucha no está resuelta. Uno puede decir que estamos en una época de consolidación de nuevas fuerzas progresistas de izquierda y derecha; pero ese poder que pueda emerger en la campaña electoral de 2018 seguro se va a caracterizar por el elemento polarizante del "paso de la guerra" y "la resistencia a la paz".

(J.A): ¿Qué hizo diferente esta negociación a las experiencias fallidas con gobiernos anteriores?

(A.P): Enfrentamos en las etapas anteriores gobiernos que no tenían la voluntad de negociar; su estrategia era ganar tiempo para fortalecer las fuerzas armadas. Eso lo expresa con mucha claridad Camilo Gómez -el comisionado de paz del gobierno Pastrana-, cuando afirma que el propósito real del gobierno era reestructurar las fuerzas armadas, dotarlas de nuevos equipos y modernizar su doctrina de seguridad.

En el gobierno de Santos está claro que hubo factores poderosos que inclinaron la balanza hacia la firma del acuerdo, con buenas intenciones de las partes, aunque no todas son santas, no todas son bíblicas. Aquí hay un cálculo frío de fuerzas de poder. Incluso, el acuerdo conviene a importantes macroproyectos económicos, especialmente los vinculados a la economía extractiva y minera, en las mismas áreas donde las Farc hacen presencia.

Jaime Wilches (J.W): Y parece que las buenas intenciones no fueron suficientes porque la sociedad colombiana no reaccionó como se esperaba. Así quedó demostrado con los resultados del plebiscito del 2 de octubre de 2016. Frente a esta experiencia ¿cuál fue la reacción de las Farc al conocer los resultados?

(A.P): Bueno, ahí en su momento ustedes vieron las distintas declaraciones de los comandantes de las Farc. Una declaración de Timochenko señalando que se reconocían los resultados, lamentando profundamente lo sucedido, pero dejando en firme el compromiso con lo acordado en La Habana. Sin embargo, más que la reacción, habría que estudiar a la distancia cuáles fueron los factores que hicieron que se impusiera el No.

Digamos que el triunfo del No es la suma de factores, como la falta de decisión social de trabajar por el Sí, la actitud ambivalente de Santos y la forma como en los negociadores del gobierno pesa todavía una visión contrainsurgente.

Por un lado, somos socios, pero por otro lado somos los enemigos que hay que vencer, esa dicotomía en la doctrina inicial se mantiene hoy en día, y en este aspecto hay que señalar que los medios de comunicación tienen una gran responsabilidad; medios que, por cierto, no se han dado cuenta que en Colombia se firmó la paz.

Una entrevista con un combatiente de la paz es una nueva emboscada, pareciera que el ejercicio de la emboscada que ya no se realiza, a ellos les quedó encantando. Los medios de comunicación más poderosos insisten en seguir informando para la guerra. Hombre, si ya firmamos un acuerdo, si ya no va a haber más insurgencia, entonces por qué existe la contrainsurgencia mediática, si ya no hay guerrilla para qué existe la doctrina antiguerrillera en las fuerzas armadas y los políticos. Ahí se reafirma una verdad y es que la guerrilla solo es un instrumento para reproducir prácticas contrainsurgentes, lo cual es un negocio muy lucrativo que permite comprar armas y glifosato, entrenamiento militar, acuerdos con el extranjero, y de eso, está comprobado, se nutren voceros del gobierno y empresarios.

(J.A): Ante las realidades que usted denuncia, el apoyo internacional al proceso de negociación, y el que sigue existiendo en la implementación, es una cuestión mucho más relevante de lo que pareciera, ¿qué tan importante ha sido que la comunidad internacional haya apoyado este proceso?

(A.P): Los contornos del proceso de paz fueron dibujados por las dos partes. Las Farc siempre presionaron por una mayor participación internacional y el gobierno trabajó por restringir la presencia internacional. Un dato curioso es que la decisión de elegir a Cuba como sede de la negociación fue propuesta por el gobierno; nosotros que tenemos afecto y cariño por la cultura socialista queríamos que los diálogos se desarrollaran en Colombia.

Les dijimos que lo hiciéramos en Venezuela, dijeron que no, y tampoco en Brasil, entonces ellos en esa etapa se les veían los esfuerzos de poner lo más lejos posible el escenario de los diálogos y la intención era que los diálogos también estuvieran sometidos al bloqueo que existe en la Isla. Pero ahí se equivocaron, porque en la época digital la figura de los bloqueos no existe. Con los medios virtuales logramos dar a conocer el proceso de paz. Nosotros teníamos una mayor presencia de garantes internacionales en todos sus niveles y categorías, pero el gobierno no le dio difusión a este hecho porque no quería que el impacto de lo que hubiera progresado ahí pudiera repercutir en las percepciones o encuestas sobre la imagen gubernamental en Colombia.

(J.W): La intención de ustedes de negociar en Colombia resulta un dato novedoso y puede ser que alejarse tanto repercutió en la ausencia de entusiasmo de la sociedad ante el éxito del proceso. Pero ¿no consideran ustedes que también ha existido una resistencia de las Farc a buscar mecanismos innovadores para conectar con los sectores que no han entendido sus proyectos ideológicos?

(A.P): La estructura militar de la sociedad colombiana es el resultado de las confrontaciones políticas que se han 
dado en el país y que finalmente han privilegiado y favorecido a la derecha colombiana. El proceso de paz, incluso la lucha armada guerrillera, fueron jalonazos importantes hacia la democratización del país.

La guerrilla no es una propuesta armada exclusivamente, sino que fue una propuesta política y que ha contribuido a la modernización del país, a la ideologización de corrientes progresistas. No es tan cierto que no se ha conectado nuestro pensamiento con la sociedad; lo que sucede es que experiencias de tránsito a la política fueron dolorosas, como es el caso de la Unión Patriótica. Esto obligó a tener prevenciones -no comprendidas- en el momento de la negociación con el gobierno. Pero también somos conscientes de que es todo un reto llegar a los sectores que votaron por el No, y que han sido cooptados por fuerzas reaccionarias que quieren sofocar los ambientes democráticos que se acordaron construir. La mentalidad de derecha de los colombianos debe ceder ante esa realidad, si el mundo ha cedido y ha cambiado ¿por qué Colombia no va a lograr esa transformación?

(J.W): Usted ha dado un diagnóstico de la innegable mentalidad de derecha en Colombia, y es cierto que las fuerzas reaccionarias movilizaron muchos votos por el No en el plebiscito, pero también es cierto que existen muchos sectores de la opinión pública informados que se resisten al acuerdo. Por eso insisto en la pregunta ¿cómo han pensado acercarse a la sociedad colombiana?

(A.P): El muro que impide la reconciliación de las Farc con la sociedad, es el construido por los prejuicios de los medios de comunicación. Entre sociedad y guerrilla nunca hubo fronteras infranqueables, una insurgencia victoriosa se desarrolla solo si interactúa con el núcleo social en el que se mueve, por eso la conexión con los sectores campesinos colombianos fue articulada, porque siempre estuvimos pendientes de sus necesidades.

En esta etapa, entendemos que debemos llegar a más sectores, y por eso una de las discusiones fundamentales en la negociación fue la necesidad de garantizar espacios informativos, para difundir las propuestas que teníamos y contribuir al equilibrio en el debate.

De manera desafortunada no se nos concedió. No logramos arrancar ni siquiera cinco minutos en los grandes canales de la televisión colombiana. Sencillamente nos remitieron a la posibilidad de abrir un canal por cable con todo el reto y la limitación que estos canales de difusiones conllevan en su intención de masificarse.

Ahí aprendimos que esta burguesía tiene clara la ecuación del poder. Hoy el poder no emana de la tierra, por eso nos dieron 10 000 hectáreas para trabajarlas, en cambio se negaron a concedernos cinco minutos de televisión. Es una estupidez creer que hay democracia sin medios de comunicación, y a esto se suma que los dirigentes no sean amenazados con la eliminación física, y de nuevo surge el problema no solo de la desinformación de los medios, sino de la permanencia de prácticas paramilitares.

Terrible sería que se confirmara una vez más la alianza entre Estado y paramilitarismo, porque eso se volvería una opción para continuar la guerra y en el acuerdo está firmado que debemos hacer esfuerzos por la no repetición. Al afirmar que no se va a repetir el conflicto, pues hay que asegurar que los factores que lo generaron no se repitan, y que en esta labor los medios puedan contribuir con el fin de no dar motivaciones para la justificación del acto violento hacia sectores sociales que piensan otro orden político.

(J.W): En relación con el paramilitarismo, ¿qué han pensado ustedes para evitar lo sucedido hace 30 años con el exterminio de la Unión Patriótica?

(A.P): Nosotros firmamos un punto sobre seguridad. Es un paquete de medidas que establecen acciones de organismos oficiales para actuar contra el paramilitarismo. Se propone que lleguemos a un gran pacto nacional por la paz que obligue a todas las fuerzas sociales y políticas a defender sus ideas por las vías democráticas. En síntesis, la ausencia de consensos crea el caldo de cultivo para la existencia de grupos paramilitares.

Hemos visto que en esta etapa no solo hay amenazas contra las fuerzas insurgentes transformadas en partidos políticos. En una marcha del pasado primero de abril, los voceros de sectores políticos como el Centro Democrático amenazaron con discursos alusivos a la guerra; oímos gritos que pregonaban tumbar a Santos del gobierno a través de cualquier esfuerzo o procedimiento, es decir, fue una acción golpista.

Tenemos una derecha envalentonada y disciplinada, pero agresiva y resistente a toda posibilidad de un acuerdo negociado con la insurgencia. Esto reafirma que la raíz de los males en Colombia se explica en la represión
Tenemos una derecha envalentonada $y$ disciplinada, pero agresiva y resistente a toda posibilidad de un acuerdo negociado con la insurgencia. violenta a un orden distinto al modelo excluyente, injusto e inequitativo.

(J.A): Además de los hechos de persecución política y amenazas a los integrantes de las Farc, existe otro problema nuclear asociado a los proyectos políticos reaccionarios: la concentración de la tierra. En esta dirección ¿cuáles son las acciones que se deben implementar para empezar a solucionar la cuestión agraria en Colombia?

(A.P): El esquema de propiedad de la tierra en Colombia es vergonzoso. Lo firmado en el punto uno del acuerdo tiene el precedente de que sí es posible hacer cambios en la estructura agraria del país. Les cuento una anécdota: durante la discusión del tema agrario nos visitó una delegación 
de las partes que firmaron el acuerdo de paz en Irlanda; cuando nos preguntaron qué era lo que nosotros queríamos en el tema agrario se rieron y nos dijeron: pero sí ustedes están luchando por el derecho a la tierra, por el Estado y la modernización de las estructuras económicas, eso nosotros lo logramos en Irlanda hace doscientos años.

Para nosotros es claro que lo exigido en la negociación no es socialista, es solo un derecho básico, que seguramente en la academia y en círculos intelectuales se comprenda, pero en quienes poseen la tierra, es una petición que pone en peligro sus intereses de mantener una estructura basada en los privilegios y la acumulación.

Adicional a lo anterior, el tema del catastro rural nos llamó poderosamente la atención, ¿cómo un país que quiere dejar atrás un legado de violencia no apoya la modernización del sistema catastral? Es obvio que ese desorden no es un problema de falta de finanzas para contratar los técnicos ni mucho menos, es la ausencia de voluntad estatal para hacer el mapa de la propiedad rural. Esto exige las limitaciones producidas en ciclos de violencia donde los títulos de propiedad fueron usurpados y apropiados bajo figuras legales, pero represivas, en las que se fue consolidando una guerra no contra la insurgencia, sino contra los campesinos o los propietarios de minifundios.

Mientras en la agenda de la política colombiana predominen tímidas reformas agrarias o sospechosas legalizaciones justificadas en estudios técnicos y catastrales, la violencia permanecerá, pues seguiremos reproduciendo una ola de inconformidades, que terminarán en nuevos conflictos, sustentados en viejos problemas. Insisto, la reforma agraria no es una necesidad del socialismo, es un principio básico del capitalismo.

(J.W): Si bien es cierto que el país necesita una reforma agraria, también es una realidad que este propósito debe tener en cuenta que ya no solo son factores locales los que están en juego, en este caso, el acuerdo de paz, como usted ya lo mencionó en líneas anteriores, enfrenta la emergencia de multinacionales y si el término se ajusta de una "burguesía global" que parece importarle más que las Farc no sean un obstáculo, a contribuir con cambios estructurales en el modelo económico colombiano ¿cómo visualiza este escenario?

(A.P): Con preocupación estamos advirtiendo que el modelo de "burguesía global" que usted plantea se va a imponer con el fin de la resistencia armada; por esa razón, hay que preparar a la resistencia civil contra esos planes. Ya hemos visto, por ejemplo, que banderas como la ecología, pasan de ser herramientas tácticas a ser cocinas estratégicas que modifican el ambiente social del campesino.

El plan es depredador, el plan es liquidar todo vestigio de vida que pueda existir en el territorio y en centros de riqueza petrolera. Les pongo el ejemplo de los municipios en el monte llanero del Meta, los ganaderos de los municipios de Granada, San Martín, Acacías, Villavicencio, Restrepo, Mesetas y quince municipios de la región, son ganaderos que apoyaron el paramilitarismo y le dieron estabilidad a un proyecto contrarreformista en la región. Esos sectores hoy están amenazados porque las aguas que bajan por la cordillera oriental vienen contaminadas con petróleo, lo que va a obligarlos a cambiar de postura y preservar el ecosistema actual porque su negocio, aunque retrógrado, es más viable que la explotación petrolera que ha sacado completamente el manto vegetal de estas regiones.

Sumado a lo anterior, hemos advertido que la erradi-
Para nosotros es claro que lo exigido en la negociación no es socialista, es solo un derecho básico, que seguramente en la academia y en círculos intelectuales se comprenda, pero en quienes poseen la tierra, es una petición que pone en peligro sus intereses de mantener una estructura basada en los privilegios y la acumulación. cación de la insurgencia va a continuar con la erradicación de nuestras bases sociales en distintos territorios, seguramente con la combinación de un plan pistolay programas económicos tendientes a la profundización de la inequidad social. En el piedemonte llanero hay oro, posiblemente uranio, suficientes incentivos para excluir proyectos agrícolas y desplazar las masas campesinas que, en dos o más generaciones, han contado con el apoyo de la guerrilla.

(J.A): ¿Cómo piensan generar cambios para que la agricultura no se vea relegada a negocios multinacionales en detrimento de los campesinos?, ¿qué es lo que quiere hacer las Farc dentro de la vida civil y política para luchar por un modelo económico distinto?

(A.P): Fue una gran pérdida haber dejado pasar la oportunidad de los diálogos de La Habana para incorporar toda la realidad social y lograr acuerdos puntuales sobre los mínimos, pero el gobierno se impuso, se cerró a la banda. El precio por pagar si seguíamos mostrando la inclusión de esos temas era que ellos sencillamente se levantaban de la mesa. O sea, fue un gesto nuestro de sensibilidad firmar los puntos del grueso del tema económico y social; sin embargo, nuestra estrategia era que, si bien no podíamos poner al elefante en la mesa, pues al menos agarrarnos de la cola y a través de la cola subirnos al elefante, es decir, cedimos en el tema económico social, pero 
no omitimos los puntos del agro, cultivos ilícitos y de participación política.

Nosotros queremos trabajar en una agenda que concientice la necesidad de abordar en serio el problema rural, como una forma incluso de resolver parte de los problemas urbanos originados, sin duda alguna, por fenómenos dramáticos como el desplazamiento forzado. Después de los acuerdos de La Habana, queda la tarea pendiente de una reforma general del país, una reforma democrática de todos; pero bueno, eso ya será una tarea que, los mismos negociadores del gobierno decían, estábamos en posibilidad de proponer en los espacios de deliberación como el Congreso de la República. Esperemos que, para ese momento, y cuando las elecciones legislativas nos hayan dado ese respaldo, no se comience con un proceso de exterminio físico y amenazas en contra de la integridad de nuestras bases.

Como ya lo había planteado, estamos en la obligación de avanzar en la conciencia de los colombianos, avanzar en que esa transformación hay que dejar de hacerla como un grupo insurgente, que se ha visto bastante aislado del conjunto de la sociedad por esa matriz mediática y contrainsurgente.

Ahora, lo que ustedes me piden, lo que ustedes preguntan es también obligación de toda la sociedad civil: academia, obreros, campesinos, directivos de universidades, dueños de medios de comunicación, empresarios, fuerzas armadas... Si el acuerdo de paz no moviliza el consenso social, seguiremos anclados al siglo XIX.

(J.W): El mensaje que usted pretende dar al invitar a diferentes sectores sociales a unirse puede entrar en contradicción con la ausencia de una izquierda unida, coherente y articulada en proyectos programáticos y no en egos políticos. Con este escenario ¿qué se ha pensado desde las Farc para dar un mensaje de unidad y reconciliación?

(A.P): Lo más triste de la época del final del conflicto y de la solución política es que, abriéndose una puerta de esperanza, presenciamos también la oportunidad perdida en Bogotá, donde se presenció la división de la izquierda y administraciones que terminaron en líos jurídicos. Pero esto no puede ser un obstáculo para detenernos en el compromiso de recrear nuevos escenarios de participación y acción política.

El punto de participación política que se defendió en La Habana estaba dirigido para todas las fuerzas; el gobierno intentó oponerse creyendo que era un exabrupto, pero
Nuestro objetivo es llegar al congreso con una izquierda que no tenga solo la representación de la izquierda urbana. Queremos apostar a un escenario electoral donde todos tengan la oportunidad de participar: campesinos e indígenas, los que tienen el barro en las botas. finalmente logramos hacer entender que nosotros no somos la representación de todos los movimientos sociales y políticos, solo somos una expresión de ese conjunto que se mueve en la misma dirección, y que, acordar esto en la mesa de negociación, era enviar un mensaje de reconciliación y de interés de la insurgencia de trabajar por los intereses colectivos y el bien común.

Por eso lo que queremos en este cuarto de hora es converger en la lucha de una agenda de transformaciones sin exclusiones. Invitamos a todas las fuerzas políticas a que aprovechen esta oportunidad, para que entre todos consigamos un poderoso movimiento político que pueda tener una manifestación corosa, ojalá triunfante en las elecciones del 2018. dispersas, lo cual impide que se tenga más influencia en Nuecion, pero a la vez como un reto para trabajar. que no tenga solo la representación de la izquierda urbana. Queremos apostar a un escenario electoral donde todos tengan la oportunidad de participar: campesinos e dígenas, los que tienen el barro en las botas.

(J.W): Entre los actores a los que usted convoca para el consenso social, tenemos especial interés en la academia, un actor que ha investigado el conflicto, lo ha indagado pero tal vez de manera autocrítica, debemos decir que hemos permanecido silenciosos, ajenos y poco propositivos frente a los problemas del país ¿Cuál cree que debe ser el papel de la academia en este momento histórico?

(A.P): La academia no es un ente abstracto, riguroso ni alejado del conflicto interno, ni siquiera del conflicto armado. Hubo un sector de la academia que se echó el fusil al hombro y prestó todo su apoyo a la contrainsurgencia. El esfuerzo en la Universidad Nacional de Colombia por comprender el conflicto se vio mitigado por un verdadero adefesio de intelectuales puestos al servicio de la contraguerrilla colombiana.

El mensaje sería para la academia democrática, esa que no se puso el fusil al hombro, pero utilizaron su pluma y la investigación para ponerse al servicio de los acuerdos de paz. El conjunto de los textos que ustedes fueron conociendo poco a poco y que las Farc presentaron como propuestas de reformas sociales, fueron elaboradas por grupos de investigación 
juiciosos, profundamente preparados que nos nutrieron de las nuevas realidades y los cambios que se venían presentando en Colombia.

Para las Farc, estas directrices de la academia fueron las que permitieron la modernización de nuestra visión, si usted no está asesorado permanentemente por la academia su discurso no va a pegar en la realidad que usted quiere transformar. Por eso estos participantes fueron muy importantes y vemos que el pensamiento democrático en algunos espacios académicos no está muerto y que ojalá la firma de la paz tenga nuevas oportunidades para que la universidad se reforme, para que el gobierno dé más recursos para la investigación y comprensión de esta guerra degradada.

Como ya lo expresé, Colombia no puede estar anclada en el siglo antepasado, y la academia es la encargada de romper todas esas ataduras crónicas que existen por falta de información y de visión por ausencia de apoyo a la investigación. Los diagnósticos realizados por profesores e intelectuales están determinando la necesidad de estos cambios que estamos diciendo, no es por falta de estudio, no es por falta de academia, no es por falta de ciencia que no se abran campos de transformaciones, lo que hace falta en Colombia es voluntad política porque todos los sectores tenemos diagnósticos, tenemos definiciones, estudios. En pocas palabras, ya tenemos identificado el problema, ahora faltan las acciones.

(J.W): En el caso de la academia ustedes saben que asistimos a una popularización de la educación en donde la mayoría de nuestros estudiantes están asistiendo a universidades de carácter privado, las cuales tienen una visión muy distinta a la formación humanista y transformadora del país, para enfocarse a una educación en el mercado laboral ¿son conscientes las Farc, de que los integrantes interesados en comenzar o terminar sus estudios universitarios, deberán adaptarse a estas nuevas realidades pedagógicas?

(A.P): Esta pregunta tiene dos dimensiones. Primero, la privatización en las condiciones de los sectores populares para ingresar a la universidad y el deterioro del sector público. Nosotros siempre hemos favorecido que la universidad pública oficial sea la principal receptora de los recursos del Estado para que se amplíen las posibilidades para los hijos de los campesinos.

Segundo, junto a la privatización de las universidades se da otro fenómeno paralelo, que es el deshielo en las capas sociales; los estratos sociales no son compartimentos estancados, es decir, los ricos de ayer hoy son los integrantes de las capas medias, los de las capas medias de ayer hoy ingresan las capas de pobres colombianos.
Con esto les quiero explicar que hemos visto que en la universidad privada se gesta un movimiento social y político en donde los dirigentes de la insurgencia han tenido buena recepción, y donde las problemáticas de acceso a recursos básicos se piensan también desde estudiantes que, al no poder ingresar a la educación pública, sienten que existe un fenómeno de exclusión en el que se ven obligados a pagar por un derecho fundamental.

En este sentido, entendemos que los integrantes de la insurgencia deben adaptarse a las nuevas condiciones de los modelos educativos, muchos de ellos articulados a lógicas neoliberales, pero también entendemos que encontraremos comunidades académicas en las que podremos aportar una visión transformadora del sentido y pertinencia de la educación, como vía para la resolución de los problemas sociales, políticos y económicos del país.

(J.W): Y en el caso de la Universidad Distrital y la intención de las Farc de formalizar proyectos para la construcción de paz ¿qué esperan ustedes de estos intentos de articulación?

(A.P): La verdad es que hay un verdadero movimiento en las universidades públicas para participar en esta etapa de reincorporación. Ahora falta es que el gobierno tenga un mecanismo que permita a la universidad ir a las zonas aledañas a desarrollar programas académicos y procesos de formación, que respondan a las expectativas y necesidades de los territorios. Somos frente a este espacio de articulación con la academia.

(J.W): Para finalizar, la revista que nosotros editamos está dirigida a un público de jóvenes investigadores ¿cuál sería el mensaje o motivación que usted daría a este público objetivo, frente a las inquietudes o temas que aún están pendientes por explorar?

(A.P): El investigador en esencia es un revolucionario que va tras la búsqueda de nuevas verdades. La investigación es un eje del desarrollo social y el fortalecimiento de la democracia. Son las fuerzas jóvenes las que actualmente luchan por un mayor presupuesto para investigación, ampliación de oportunidades para la formación posgradual y garantías en la organización de movimientos sociales. Soberanía, independencia, democracia y justicia social sin investigación social son una entelequia. Ahí están los jóvenes en su tarea dinámica y muy importante en pleno siglo XXI, para evitar que el conformismo termine por invadir todas las capas de la esfera pública. Hemos integrado grupos de investigadores que suministran elementos para la reestructuración del programa de gobierno que llevaremos, si logramos crear una gran convergencia en el 2018. Son ellos, el motor que sigue impulsando el cambio. 